\title{
Julio Antonio de la Rosa y el grupo Pajaritas de Papel
}

Resumen: Julio Antonio de la Rosa es, sin duda, uno de los intelectuales de la vanguardia insular que, con su actitud y su obra, representa el fervor creativo que caracterizó a muchos de los autores de la primera vanguardia insular. Una prueba de ello, como pretendemos mostrar, es su labor dentro del grupo Pajaritas de Papel, tertulia interdisciplinar en la que se agruparon algunos de los protagonistas más destacados del panorama intelectual de entreguerras en Canarias.

Palabras clave: Crítica literaria, lírica, vanguardia, Julio Antonio de la Rosa, Pajaritas de Papel.

Julio Antonio de la Rosa and Pajaritas de Papel's group

Abstract: Julio de la Rosa is undoubtedly one of the island's avant-garde intellectuals who, through his attitude and his work, represents the creative enthusiasm that characterized many of the island first avant-garde authors. It is our intention to show as a proof of this his work in the Pajaritas de Papel group, an interdisciplinary gathering formed by the key people in the intellectual landscape of the interwar period in the Canaries.

Keywords: Literary criticism, lyric, avant-garde, Julio Antonio de la Rosa, Pajaritas de Papel. 


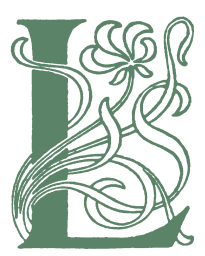

a variedad interdisciplinar del grupo Pajaritas de Papel sedujo desde muy pronto al poeta y pintor Julio Antonio de la Rosa. Pajaritas fue la primera tarima creativa que tuvo nuestro joven poeta para expresar sus inquietudes artísticas a través de la publicación de poemas, la ilustración de algunos de los cuadernillos manuscritos que el grupo preparaba y presentaba en privado, y la participación en las representaciones teatrales del grupo -cuyos decorados ayudaba a preparar el propio Julio Antonio-, además de ser partícipe en sus «acciones», como las llama Eduardo Westerdahl (1929). Este círculo de amigos se encargó de publicar, probablemente bajo la batuta del propio Westerdahl, una selección de la obra de Julio Antonio, en una edición limitada de 300 ejemplares que llevará por título Tratado de las tardes nuevas ${ }^{1}$; además, muchas de las composiciones recogidas en esta obra están dedicadas, como veremos, a componentes de esta tertulia. Si a esto agregamos que las primeras reuniones del grupo se realizaron en la casa de Julio Antonio, trasladándose estas, finalmente, con carácter definitivo a la casa de Carmen Rosa Guimerá, según nos comenta José María de la Rosa (1977), hermano de Julio Antonio y también poeta, se aprecia con claridad el íntimo vínculo existente entre el poeta y este grupo de creadores:

Tengo que dar un poco marcha atrás para situarnos en los años en que comenzaron a dar muestra de vida activa, aquellos hombres -al menos los principales-, que después compusieron la redacción de «Gaceta de Arte». Este tiempo sería el transcurrido desde 1925 al advenimiento de la República. Había por entonces en Santa Cruz un grupo de jóvenes, -muy jóvenes-, escritores que componen «Pajaritas de Papel» [...].

Casi todos los hombres que primitivamente formaron las filas de «Pajaritas de Papel», continuaron sus lecturas y jamás le perdieron la cara al tiempo en que vivían. Por el contrario fueron cobrando lentamente posiciones más y más actuales, especialmente por sus contactos con el extranjero; hasta que los viajes por Francia y Alemania de Eduardo Westerdahl, pusieron en marcha la idea de crear una revista de alto contenido intelectual, y esta fue «Gaceta de Arte» [...].

\footnotetext{
1 El poemario se edita en 1931, con un prólogo que, probablemente, también escribió Eduardo Westerdahl. En el número 2 de la revista La Rosa de los Vientos (mayo de 1927) aparece, junto al poema «XVII (Día de aire)», la nota «Del Tratado de las tardes nuevas», primera ocasión en que aparece el que será el título de su único libro de poemas.
} 
José María de la Rosa asiste como testigo de excepción en estos momentos a la gestación y posterior desarrollo de esta singular familia artística, que realizó algunas de sus reuniones y algunas de sus particulares publicaciones, como la de un periódico denominado Interior o las ediciones de versos y actividades plásticas², en el «despachito» de la casa azul, lugar de residencia en la calle Barranquillo de la capital santacrucera de los dos hermanos. Hemos de añadir que traemos a colación este dato porque José de la Rosa ve una insoslayable continuidad desde la creación de Pajaritas, vista como un avance en la cultura artística en Tenerife en los años veinte, hasta el nacimiento de Gaceta de Arte, pues muchos de los poetas y críticos agrupados en la revista capitaneada por Westerdahl estuvieron, junto al propio autor de Poemas de sol lleno (1928) en Pajaritas de Papel.

Entre 1925 y 1927 comenzó este grupo a realizar sus primeras reuniones. Sin embargo, la actividad artística de Pajaritas tiene su apogeo en los dos años siguientes, 1928 y 1929, cediendo este ímpetu su intensidad a comienzos de la década de los años $30^{3}$. Con anterioridad a estas dos últimas fechas, la actividad del grupo consistía en hacer reuniones en las que el juego, la diversión y la risa eran los objetivos perseguidos.

Fue Eduardo Westerdahl quien sacó a relucir las principales acciones de este iconoclasta grupo santacrucero, acciones caracterizadas por la espontaneidad, la ingenuidad, la creatividad y el juego. Con razón M. ${ }^{a}$ Isabel Navarro Segura (1997: 23-73) considera a este grupo como una auténtica «conciencia auroral»; y es que los componentes de Pajaritas de Papel comenzaban a tomar plena conciencia del momento de convulsión y de cambio que vivían y que, poco a poco, se estaba gestando en el marco de la cultura insular, un cambio en busca de la modernidad. Así justifica Westerdahl (1929), esta actitud aperturista hacia nuevos horizontes creativos:

\footnotetext{
2 Sobre Pajaritas la profesora Pilar Carreño (1998) organizó una interesante exposición, que tuvo lugar entre los días 21 de diciembre de 1998 al 5 de enero de 1999 en la sala cultural «La Granja» de la capital tinerfeña, y que dio lugar al catálogo Pajaritas de Papel. La frágil seducción. En opinión de esta autora (1998: 33), «el campo de acción de Pajaritas de Papel se despliega como un abanico multicolor a ámbitos que potencian la imaginación y la creatividad, capaces de transformar actos de la vida cotidiana en acciones artísticas de carácter colectivo, [...].»

3 De hecho, Pilar Carreño (1998: 19, nota 15), puntualiza que «el grupo deja de funcionar después de la trágica muerte del poeta Julio Antonio de la Rosa (30 de agosto de 1930)».
} 
El lector inteligente habrá apreciado que este grupo no tiene tendencias, ni ismo determinado, que no está encasillado en la abstracción de un grupo de los llamados de vanguardia. Es, eso sí, una novísima manera de arte, una interpretación moderna de la vida, una tolerancia ecléctica, donde cada época se valora sinceramente desde el minué al jazz, cogiendo siempre de la historia los valores olvidados para su reconstrucción moderna.

Muchos de estos rasgos pervivirán en la poética de Julio Antonio de la Rosa: en realidad, el espíritu que alentó la conformación del grupo Pajaritas le acompañaría siempre. Así, por ejemplo, es difícil encasillar a Julio Antonio en un ismo determinado, si bien es cierto que en su producción serán pilares destacados tanto el neopopularismo ${ }^{4}$ como el ultraísmo aunque, lo que más bien realizó -o le dio tiempo a realizar-, fue una síntesis de esos ismos vanguardistas. Del mismo modo, en Julio Antonio también se da una reconstrucción moderna de valores olvidados, especialmente a través de la reinterpretación que hará del cancionero infantil, con poemas de tonalidad lorquiana como el que dedica a la componente de Pajaritas Mari-Sol -«[María Sol trigo moreno]» de Poemas ingenuos (1928)-, «La pájara pinta» o «La gallina ciega».

Siguiendo con los contenidos que Westerdahl desarrolla en su artículo sobre las actuaciones de Pajaritas, destaca la realización de un «baile de lo cursi ${ }^{5}$-denominación que nos recuerda a Ramón y sus excentricidades-, y que no es más que una burla de la pomposidad y boato de los bailes decimonónicos ${ }^{6}$; también destaca la representación de distintas obras teatrales como Mariana Pineda, de García Lorca, o El señor de Pigmalión, de Jacinto Grau, obras en las que Julio Antonio participó como actor y como artífice de los decorados. Además, sabemos por Pérez Minik que colaboró en las representaciones de obras de Azorín y de Bernard Shaw que se realizaron en el Círculo de Bellas Artes de Santa Cruz?

\footnotetext{
4 En su estudio sobre «Los poetas de Gaceta de Arte», Isabel Castells (1997: 174) destaca ese carácter popularizante de algunas de las composiciones de Julio Antonio.

5 Hemos de señalar que uno de los rasgos característicos de este grupo era su desprestigio absoluto del artista considerado como un ser superior. Es por ello por lo que se burlan de las reuniones ateneístas y de las fiestas de la generación anterior, algo que posteriormente autores como Agustín Espinosa llevarán hasta sus últimas consecuencias.

6 Y si hablamos de excentricidades, una de estas acciones estrafalarias fue la celebración de «La corrida de Toros», «celebrada en el patio trasero de la casa de Carmen Rosa Guimerá; Minik hacía de torero y Julio Antonio de toro con unos cuernos que le habían prestado» (Pilar Carreño, 1998: 35).

7 Pérez Minik (1952: 279). Las obras se titulaban, respectivamente, Old Spain y Cándida. Las representaciones se hicieron bajo la dirección, de Pedro Ramírez Vizcaya.
} 
En este artículo, que contiene significativas revelaciones, Westerdahl se detiene, además, en un aspecto que enlaza directamente con la estética de vanguardia tan cercana a nuestro poeta: «Pajaritas de Papel [es] una consecuencia del resurgimiento de la isla». Este fue un grupo que quiso tomar plena conciencia del despegue artístico de la(s) isla(s) ${ }^{8}$. En este sentido, ya el propio Westerdahl (1926), en otro artículo publicado en La Prensa, decía lo siguiente: «he tomado siempre, como motivo principal de mis crónicas, el comentario, [...], de una nueva generación, acorde con las exigencias del arte nuevo y como reflejo de la inquietud mundial [...].» Con esto vemos que una de las puertas del cambio, aunque solo sea una puerta de «acceso restringido para los socios ${ }^{9}$, la abre Pajaritas de Papel, cuna de futuros poetas y teóricos de la vanguardia en Canarias.

La «conformación artística» de este "círculo absurdo» es, en palabras de Eduardo Westerdahl (1929), la siguiente: «[el grupo] está integrado por aficionados y profesionales de música, canto, pintura, teatro, decoradores, escritores, fotógrafos, deportistas. Las actividades personales, se intercambian, se contagian, [...]» ${ }^{10}$. Pilar Carreño (1998: 22) nos amplía estas impresiones de Westerdahl:

\footnotetext{
8 Según Pilar Carreño (1998: 42) es «el primer grupo de vanguardia surgido en el contexto insular, cuya tendencia es la no tendencia, lograda por una sutil amalgama de lenguajes vanguardistas- [...]».

9 Estos socios -cuyo pseudónimo en el seno de la tertulia anotaremos en cursiva- que componían el grupo son (Navarro Segura, 1997: 39): los poetas Julio Antonio de la Rosa y José Antonio Rojas, las pianistas Victoria Carvajal y Amor Lozano, las hermanas Ferrer (María -apodada Intermitente- y Hortensia Ferrer Piñeiro), Ernesto Guimerá, José Miguel Mandillo, Emma Martínez de la Torre -Anaga-, las hermanas Hilda -Hil o Hildanilda- y Rosa Gómez Camacho -Rossini-, Domingo Pérez Minik -Minik- y Eduardo Westerdahl -que participaba como Dandín-. A estos nombres hemos de añadir los de Selina Calzadilla Izquierdo, llamada por los miembros del grupo Celi o Reginacaeli, María Armendáriz -Maruchi-, Consuelo Díaz Hernández -Consuelete-, Pedro García Cabrera, María de la Soledad García de Paredes -Mari-Sol-, Manuel Parejo Moreno, Jesús Pérez Hernández y María de los Ángeles de la Rosa López-Abeleda, hermana de Julio Antonio, que recibía el sobrenombre de Mariita. Es sintomático que en este listado Navarro Segura no cite a Carmen Rosa Guimerá -Nivaria-. Por otra parte, la profesora Pilar Carreño Corbella (1998) no cita como miembros del grupo ni a José Antonio Rojas ni a Juan Ismael, como sí hace, en cambio, Esteban Amado (1985) y, sin embargo, sí incluye a Domingo López Torres y a Ernesto Guimerá Martínez, nombres con los que queda ya más o menos definido el plantel que integraba esta tertulia.

10 Julio Antonio ejerció en el grupo como poeta, pintor y actor. En el caso de la fotografía, podemos hacer referencia al propio Westerdahl, quien nos ha dejado un espléndido legado fotográfico en el que aparecen personalidades como André Breton, Jacqueline Breton y Benjamin Péret en su visita a Tenerife con motivo de la exposición surrealista que Gaceta de Arte realizó en mayo de 1935. Dentro de los deportistas hemos de referirnos a Domingo Pérez Minik, quien firmaba sus crónicas deportivas en Hespérides y en Gaceta de Tenerife con el pseudónimo de Minik.
} 
En Pajaritas de Papel, aunque se trata de una sociedad anónima y limitada, figuran involucrados con distinta intensidad algo más de una veintena de jóvenes de ambos sexos, pertenecientes a familias de la burguesía de Santa Cruz, con numerosos vínculos de parentesco entre ellos y que vivían a escasos metros unos de otros. Se relacionaban, en su gran mayoría, con el mundo de la cultura -teatro, música, canto, literatura, pintura, fotografía, cine...-, aunque los focos más importantes de interrelación antes de conformarse en grupo lo constituyen la revista Hespérides, que actúa como una plataforma literaria, y el Circulo de Bellas Artes de Santa Cruz, canalizador de las inquietudes artísticas y musicales, a través de las actividades programadas por las distintas secciones.

Con esta cita queda desmentida la opinión de algunos críticos que, por un lado, postulan que «bajo esta denominación [Pajaritas de Papel] se acogió un grupo de jóvenes escritores» ${ }^{11} ; \mathrm{y}$, por otro, la de quienes opinan que era exclusivamente un «grupo teatral» ligado al Círculo de Bellas Artes de Santa Cruz. Hemos de decir que no todos los miembros de este grupo participaron en actividades teatrales; es más, muchos de ellos ni tan siquiera se dedicaban a las artes escénicas. Y es que el teatro solo era una de las tantas facetas que este grupo aglutinador de distintas tendencias artísticas desarrolló.

Julio Antonio fue uno de los miembros que más se implicó en la actividad del grupo: participa en una velada literario musical en el Puerto de la Cruz, representando la obra Un buen reclamo, de Arturo Humanes y Miranda; también como actor interviene, junto a Pérez Minik, en la representación del sainete en un acto de Fernández de Villar La mujer de su casa, y el paso de comedia en un acto Por qué sí, de Linares Rivas; asimismo, forma parte de la escenificación de la comedia en tres actos de Muñoz Seca titulada El ardid. Junto a su labor de actor, realiza los decorados de la opereta El príncipe bohemio, que se llevó a escena en el teatro Guimerá ${ }^{12}$.

Pajaritas de Papel, como antes hemos mencionado, era una tertulia con carácter privado ${ }^{13}$. Los lectores de sus manuscritos eran los propios componen-

11 En cuanto a la primera afirmación, concretamente nos referimos a un comentario de Jorge Rodríguez Padrón (1992: 233); con respecto a la segunda, véase Bonet (1995: 539).

12 Sin firma, «El arte de nuestros aficionados», Gaceta de Tenerife, Santa Cruz de Tenerife, 9 de mayo de 1926. «La obra fue presentada con gran lujo, no omitiéndose detalle alguno, pues hasta las decoraciones se pintaron ex profeso [sic] para dicha obra por el distinguido joven Julio de la Rosa».

13 En el artículo de Eduardo Westerdahl (1929) nos encontramos con expresiones como las siguientes: «Las reuniones diferentes siempre, son absolutamente privadas»; Pajaritas de Papel «es una sociedad li- 
tes, siendo la circulación de estos trabajos muy limitada. La mayor parte de esas publicaciones se editaba en un solo ejemplar:

Los libros son hechos a mano, en escritura, encuadernación e ilustraciones. La parte literaria -siempre sobre un tema determinado tratado a escote- es variada con entera libertad personal de la manera artística de cada pajarita. Los originales pacientes filigranas de entusiasmo (Westerdahl 1929).

Emeterio Gutiérrez Albelo (1987: 37), con su tono habitual de tintes líricos, tildará la actividad de este grupo como «música de cámara de aquel caracolíneo grupo de Pajaritas de Papel». Esa privacidad no impidió, en cambio, que su actividad cultural fuese notable.

En la faceta editorial, Julio Antonio tuvo una importante participación en la edición, composición e ilustración de estas publicaciones. La editorial del grupo, Chez-Nous, publicó un total de diez volúmenes ${ }^{14}$. En algunos de ellos podemos encontrar composiciones inéditas como, por ejemplo, las tituladas «Miércoles»y «Noche», en el volumen Viaje a la China (1928); en Siluetas 1830-1930 (1928) también participa con dos poemas, «Vanguardismo 1928» y «Romanticismo 1830»; en Maruchi-Historia de una niña bien (1928), colabora con un texto en prosa titulado «Flirt Dancing» y, finalmente, en Flor-Klore (1928) incorpora el poema «[El girasol amarillo]».

En lo que a su participación «no literaria» en Pajaritas de Papel se refiere, de la Rosa confecciona -y empleamos este término dado el carácter artesanal de todas las acciones del grupo- junto con Nivaria -Carmen Rosa Guimerá- la edición de Poemas de Lux (1929), volumen que tenía forma de flecha y que, probablemente, fue el último que se realizó en el seno del grupo. En Astronomía (1928) aparece una ilustración suya, con el sintomático título de «Noche negra»; y, en fin, en Interview (1928) concede una entrevista, a medio camino entre el humor y la seriedad, que los hacedores de este volumen, -Nivaria y Dandin-, titulan «Julio Antonio, poeta y militar romántico».

mitada, sin constitución legal ni formal reglamentación»; en otra ocasión Dandín hablará de «anónimo grupo».

14 Esos volúmenes son: Maruchi-Historia de una niña bien, Impresiones y chispazos, Flor-Klore, Astronomía, Interview, Viaje a la China, Siluetas 1830-1930, Poemas de Lux, Almanaque y Suplemento. Casi todos datan de 1928 salvo Poemas de Lux, volumen de 1929. A estas publicaciones hay que añadir que el grupo tenía otros proyectos editoriales que llevarían los siguientes títulos: Itinerario fantástico de Santa Cruz de Tenerife, Arquitecturas y decoración interior y Traducciones. 
Con Navarro Segura (1997: 42) consideramos, sin duda, que «el episodio de Pajaritas es una refrescante experiencia iniciática y colectiva [...]. Representa un reconocimiento del poder de significación del arte y una exploración del concepto del absurdo». Y será la vena lírica la que mejor defina, como veremos, la actitud de Julio Antonio de la Rosa en Pajaritas.

Los poemas que, dentro del Tratado -seis en total-, van dedicados a componentes de Pajaritas son: de Poemas varios (1927), «Semblanza»; de Poemas ingenuos (1928), «[María Sol trigo moreno]»; del Tratado de las tardes nuevas $(1929)^{15}$, «[Tarde nueva]», «[Tres veredas, dos veredas, mi vereda]», «[Domingo en el pueblo]»y, «Retrato». Hemos de recordar que el poema, «Lux», apareció en de la publicación manuscrita Poemas de lux (1929), con el título de «Lux indigo».

El poema «Semblanza» $(60)^{16}$ es una buena muestra de poema-cuadro que encauza su expresión dentro de la estética ultraísta:

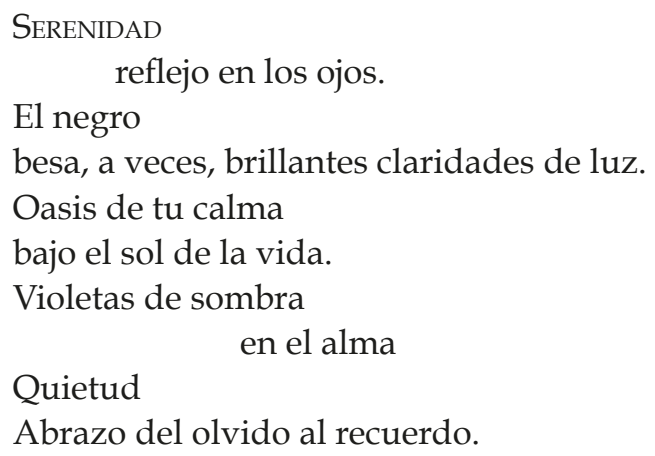

del ciprés soñador.

Simbólico beso a la luna pálida,

$[\ldots]$

La disposición caligramática del poema, que por su ritmo y dicción muy marcados recuerda los versos de «Ecovio», de Emeterio Gutiérrez Albelo

\footnotetext{
15 Hemos de aclarar que, bajo esta denominación, se encuentran tanto el poemario completo de Julio Antonio, publicado en 1931, como el cuarto viraje lírico de este mismo poemario, que recoge textos compuestos en torno a 1929.

16 Para la cita de los poemas del Tratado tomaremos como referencia la edición facsímil publicada en 1994, con una introducción de Isabel Castells, consignando junto al título del poema la página en que aparece entre paréntesis.
} 
(2007: 17-18) y, también, al poema «Noche», publicado en Viaje a la China (1928), uno de los álbumes de Pajaritas, aprovecha la significación visual del texto. Los metros regulares de corte tradicional dan paso a una estructura poética más intelectualizada. Pedro García Cabrera (1933), a quien también se ha relacionado con este grupo, nos muestra su peculiar visión de este poema y de los que, como él, se adhieren al movimiento ultraísta:

Julio Antonio descompone los poliedros poéticos de este período, en dos columnas, en un debe y haber de contable. En el cuerpo principal del poema dispone las imágenes centrales. En la segunda columna ordena los complementos poéticos, los elementos precisos para mayor esclarecer el sentido de la idea madre.

Es el Tratado de las tardes nuevas (1929) el conjunto poético que mejor plasma la poética ultraísta, ausente en el libro siguiente, Poemas Ingenuos, y que coincide en el tiempo con el «apogeo editorial» de Pajaritas de Papel. En Poemas Ingenuos se entrelazan los anhelos de niño del poeta, lo que nos trae a la memoria el ludismo desenfadado de Pajaritas de Papel. El hecho poético se convierte en puro juego sin trascendencia. $\mathrm{Si}$, como creemos, esta conciencia creadora ya estaba en el programa artístico de Pajaritas de Papel, hemos de aclarar una idea básica: este grupo no fue nunca ni un movimiento artístico ni un grupo de orientación surrealista:

Este movimiento, calificado como secreto para el resto de los mortales, aglutinó a una serie de intelectuales y creadores cuyas experiencias estéticas fueron desarrolladas en distintos campos artísticos, como la pintura, la poesía, la música y una serie de acciones de profundo aire surrealista ${ }^{17}$.

Muy probablemente afirmaciones como esta se sustenten en el hecho de que intelectuales como Eduardo Westerdahl o Domingo Pérez Minik fueron pilares esenciales en la conformación del espíritu que animó una publicación como Gaceta de Arte. En este sentido, también hay que enfatizar que se ha considerado a los dos autores citados como los «cabecillas» del grupo santacrucero, juicio que tampoco tiene sentido. Es claro que ni Pérez Minik ni Westerdahl fueron los ideólogos de este grupo sino, más bien, dos miembros

17 Archipiélago Literario, suplemento cultural del periódico El Día, Santa Cruz de Tenerife, $\mathrm{n}^{\circ}$. 275, 15 de diciembre de 1998. El artículo, sin firma, viene antecedido por un titular muy sugerente: «Pajaritas de Papel, un halo de surrealismo». 
más que participaron activamente en sus propuestas creativas y cuya trayectoria intelectual, por fortuna, está llena de brillantes paradas en el terreno de la cultura insular de vanguardia.

En otra de las colaboraciones de Julio Antonio en las ediciones manuscritas del grupo, titulada «Julio Antonio, poeta y militar romántico», una entrevista que le hicieron Carmen Rosa Guimerá y Eduardo Westerdahl ${ }^{18}$, nuestro joven escritor afirmó: «dado el momento actual, [la vanguardia] ya es pasado; dado el minuto futuro es no existir. Renovación constante no es obra, pues no tiene usted ni concepto. Alto en la marcha es quedarse atrás ¿dónde está la vanguardia?». En efecto, la vanguardia siempre está siendo y, como el tiempo, es inaprensible en su devenir como cúmulo de constantes rupturas. La vanguardia en esa andadura puede retomar elementos o aspectos pretéritos, como el rico acervo del folclore infantil ${ }^{19}$, especialmente en un territorio tan conservador en este sentido como Canarias. Julio Antonio transita por los caminos de la vanguardia sin saber cuál es su destino ni cuál es su meta: estar en la vanguardia es ir en búsqueda de la voz propia:

PREGUNTA.- ¿Por qué hace usted sus poemas infantiles después de «correr una juerga»?

RESPUESTA.- Es despertar de un rojo palpitante a pasar los labios resecos en el cristal de un agua pura, dentro de un vaso claro que alimente un crisantemo despeinado y blanco. De un ángulo a otro del alma pasa la diagonal de un rayo de sol de invierno. Oro nuevo de moscas.

Volvemos aquí a relacionar vanguardia con tradición. La vanguardia implica ruptura pero, como toda ruptura, si tomamos la definición que antes daba Julio Antonio, la vanguardia también es un hecho fundacional, un nuevo despertar. Vanguardia y tradición conviven y se comunican: la vanguardia hace que la tradición, ese «crisantemo», se renueve sin dejar de ser tradición y mantenga su significado primigenio, que ahora intensifica su vigor. Hacemos estas reflexiones porque Julio Antonio intenta, como hemos visto, definir la vanguardia como hombre crítico -desde fuera-; pero es que también

18 Esta entrevista, que tiene mucho de absurdo y nada de surrealismo, apareció en la publicación Interview (1928).

19 Según Pérez Corrales, «el neopopularismo no será sino otro instrumento contra la retórica del siglo XIX, por la sencillez y autenticidad de sus creaciones» (1986: 156). 
lo intenta como poeta en el único lugar posible: el poema. Esta conciencia metapoética la vemos en «Vanguardismo 1928»:

Es triunfo de acero

Niña amarilla

Del camino que espera.

Los ojos verdes

Una y otra vez

Tras la maraña

Que enredó su soñar

Vuelve a las cinco

Besos de su alma

Besos de sal y espuma

De colores como gran

cristalera de una iglesia

Cilíndrico ojival

Todos sus sueños

son un cigarrillo

$\mathrm{Y}$ despacio fumar.

Hemos de relacionar este poema con el titulado «Romanticismo 1830», que aparece en la misma publicación:

En la mano la frente reclinada

los ojos negros de gentil mirar, pálido el rostro, triste la cansada

expresión de los labios al soñar.

Como oración de bruscas transiciones

al decir o al rezar

Se cruzan las fantásticas

visiones

de horas que sonríen al pasar.

Sufrir es lema y en la encrucijada

de la calleja tortuosa y negra

Sintió de la amargura el hondo

Y adherida su espíritu a la hiedra

$$
\text { peso }
$$

del dolor y el placer, al hada

mala

Fundió sus labios y estampó un beso. 
Sintomáticamente, ambos poemas aparecen publicados uno frente al otro, representando visualmente la idea de espejo: la vanguardia parte del Romanticismo ${ }^{20}$, movimiento artístico y vital que supuso un cambio en la conciencia del arte; pero también se enfrenta a él, y significa una ruptura fundacional con respecto al mismo. El segundo de estos poemas, nos presenta una poetización de tópicos del creador romántico: tristeza, ensoñación, «fantásticas visiones», sufrimiento, luces y sombras, misterio, muerte. El estado de ánimo del poeta está por encima de todo en la creación. El poeta se alía con el otro lado de la vida y busca en la «realidad oscura» la verdad poética. «Vanguardismo 1928», en cambio, destierra la anécdota sentimental. La vanguardia es un camino que nunca se acaba de recorrer y en su transcurso el poeta intenta convertir en realidad poética la realidad del instante, esos «besos de sal y espuma», eternizándolos a través de la imagen. Además, la vanguardia es «triunfo del acero», que es frialdad, dureza: el sentimiento es negado como punto de partida para hacer el poema y se fija más el poeta en otros aspectos como, por ejemplo, los resultados que producen las asociaciones insólitas a través de imágenes que infunden nuevos valores a las palabras o introduciendo en la creación palabras consideradas tradicionalmente como poco poéticas (términos derivados de las ciencias técnicas, como ese «cilíndrico ojival»).

Este aire vanguardista llega a su plenitud en el poema «Tarde nueva» (89), dedicado a Eduardo Westerdahl, cuyo motivo genésico es el molino, símbolo de la modernidad. Este motivo es, para Agustín Espinosa, «signo de Occidente»:

Las palmeras de Tinajo son las palmeras que hacen mejor la rueda. Esconden su orientalismo mítico, para descubrir el tema horizontal de las higueras y de los viñedos. Pero más que palmeras enanas son molinos experimentales. $[\ldots]$

Molinos verdes. Molinos vegetales. Enanos de barbas giratorias, cabeza calva y pies subterráneos. Aprendices de molino. Muchachos jugando a los molinos sobre la baya estepa descamisada.

20 «La vanguardia es una intensificación de la estética del cambio, inaugurada por el Romanticismo». Octavio Paz (1993: 161). 
Molino: signo de Occidente. Palmera: signo de Oriente. Las palmeras de Tinajo -las palmeras que hacen mejor la rueda- han sumado los dos signos para avisar el bizantinismo cercano [...](1988: 43).

Julio Antonio también está abierto a estos nuevos aires poéticos:

\author{
TARDE nueva. \\ El molino se hizo ruleta al viento. \\ Juega el azul del cielo \\ contra el azul del mar. \\ $[\ldots]$ \\ El molino se rinde, \\ cansa su movimiento \\ a las brujas del aire. \\ La equis quiere soñar.
}

Probablemente, esta composición se inspira en un artículo del propio Westerdahl, del que reproducimos los aspectos que, a nuestro juicio, atrajeron a Julio Antonio:

Para nuestra personalidad isleña, girándula con eje clavado en el Atlántico, molino estático de masa, volteando la flexibilidad de sus aspas aparentemente aventureras, pero de radio igual, de valor por tanto masa estática, los medios externos toman prestigio y adquieren decisión influyente. Por ejemplo: el molino sin viento no muele trigo.

En nuestro desenvolvimiento local, la isla -molino- es agitado actualmente por una racha ventolera de simpatía. [...]

El hogar nuestro es esencialmente de puertas abiertas al Atlántico. No podemos vivir mascando siempre los motivos regionales de pequeña busca y encuentre. De hora en hora esa barra imantada del puerto nuestro apresa un caudal turístico que deja en la personalidad popular la huella de un paso decisivo [...] (1927).

La tarde, una vez más, se convierte en «la vereda» del poeta. Esta es la idea que encierra la composición número 7, «Tres veredas, dos veredas, mi vereda» (91ss): el poeta construye un ingenioso camino de versos, primero en 
orden descendente y después en orden ascendente. La arbitrariedad imaginativa del poeta traza un paisaje de geometrías, como, en el poema anterior, lo hace el molino al ondear al viento:

$[\ldots]$

Mi vereda:

La primera:

El triángulo de sus ojos.

(Veo brillar tardes nuevas).

El alma del pescador

ha comprado blusa seda. [sic]

La segunda:

El segador ha quebrado

la hoz de oro en una piedra.

La tercera:

La tarde en blusa de viaje

va en vagón de primera.

El triángulo de sus ojos

se ha abatido en una recta ${ }^{21}$.

La aparición de guarismos en el poema es también síntoma de la nueva poesía, pero en Julio Antonio notamos un mayor interés por los números ${ }^{22}$, en este caso, por el número tres -el triángulo: agua, tierra, cielo [tarde]-. No parece, pues, descabellado pensar que esas «tres veredas» tengan como significado último la síntesis espiritual que realiza con esos elementos, que corresponde al creador -poeta-: el pescador, el segador y la tarde representan esos tres momentos que llevan como resultado la síntesis final, la recta.

En consonancia con este interés por el número 3 está el último poema del Tratado, «Retrato» (102), dedicado a Selina [Calzadilla Izquierdo]-; y aquí no

21 Semejante actitud juguetona la encontramos en Rafael Alberti (1990: 93):

Tres veredas:

mi querida, la del centro;

la mariposa, la izquierda;

y el saltamonte guerrero,

saltando, por la derecha.

22 En Últimos Poemas (1930) tiene dos composiciones que, sintomáticamente, llevan por título «Ensayo en siete»y «Ensayo en cuatro». 
podemos más que recordar al pintor -tan presente en otro texto que salió a la luz en las publicaciones manuscritas del grupo titulado «Miércoles» (Viaje a la China, 1928). La composición se estructura en tres partes, retrato-evocación-psiquis, y comienza con una alusión a Van Dyck, pintor flamenco y uno de los retratistas más importantes y prolíficos del siglo XVII, así como uno de los más brillantes pintores en el manejo del color; podríamos decir que es una cita por afinidad:

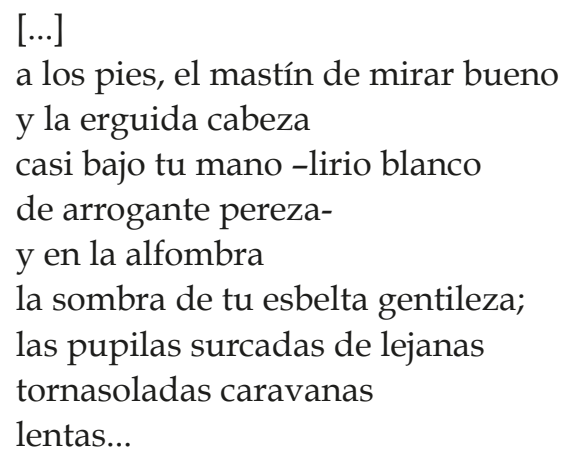

En un determinado momento del poema parece como si los encabalgamientos intentasen emular las decididas líneas continuas de la mano del pintor en este cuadro dentro del cuadro, que manifiesta la conciencia que del arte poético tenía el propio Julio Antonio.

En otro poema, «Domingo en el pueblo» (96ss), dedicado a Carmen Rosa Guimerá, se mezclan el tono de la poesía moderna y sus cadencias transparentes con el mundo rural y sus gentes -neopopularismo con ecos juanramonianos-, un mundo que es visto con una actitud positiva, dejando de lado el carácter opresivo que puede presentar el ambiente rural:

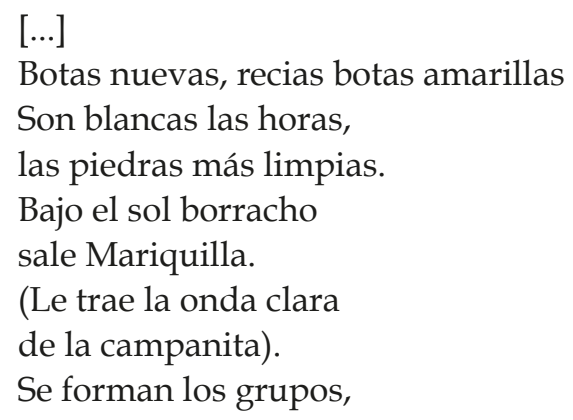


la charla se anima,

Domingo en el pueblo

La gente va a misa.

También Gutiérrez Albelo (1989: 33) posa sus ojos nuevecitos en esta atmósfera rural:

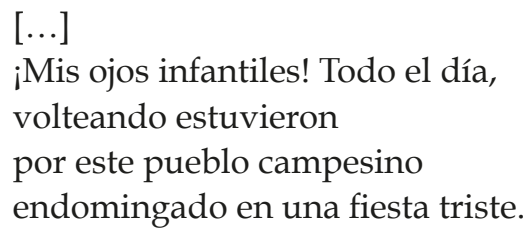

Es claro, pues, que en la trayectoria lírica de Julio Antonio de la Rosa hay una continuidad creativa, a la par que una coherencia de sentido incuestionable, entre su labor como miembro de Pajaritas de Papel y su trayectoria como poeta ligado a la primera vanguardia insular.

\section{REFERENCIAS BIBLIOGRÁFICAS}

(1926), «El arte de nuestros aficionados», en Gaceta de Tenerife, Santa Cruz de Tenerife, 9 de mayo.

(1998), «Pajaritas de Papel, un halo de surrealismo», en Archipiélago Literario, suplemento cultural del periódico El Día, Santa Cruz de Tenerife, $\mathrm{n}^{\circ} .275$, 15 de diciembre.

(2003), La rosa de los Vientos, ed. facsímil, estudios de Alejandro Krawietz y Carlos Brito, Santa Cruz de Tenerife, CajaCanarias.

Alberti, Rafael (1990), Marinero en tierra. La amante. El alba del alheli, ed. de Robert Marrast, Madrid, Castalia.

Amado Santana, Esteban (1985), Pedro García Cabrera. En torno a una existencia poética, Santa Cruz de Tenerife, ACT.

BONET, Juan Manuel (1995), Diccionario de las vanguardias en España (19071936), Madrid, Alianza. 
Carreño Corbella, Pilar (1998), Pajaritas de Papel. La frágil seducción [Catálogo de exposición], Viceconsejería de Cultura y Deportes, Gobierno de Canarias.

Castells, Isabel (1997), «Los poetas de Gaceta de Arte», en Emmanuel Guigon (coord.), Gaceta de Arte y su época, Las Palmas de Gran Canaria, C.A.A.M., págs. 159-177.

EspinOsA, Agustín (1988), Lancelot $28^{\circ}-7^{\circ}$, ed. de Nilo Palenzuela, Santa Cruz de Tenerife, Interinsular Canaria.

GutiérRez Albelo, Emeterio (1987), Poemas surrealistas y otros textos dispersos (1929-1936), ed. de Andrés Sánchez Robayna, La Laguna, Instituto de Estudios Canarios.

- (1989), Campanario de la primavera. Romanticismo y cuenta nueva. Enigma del invitado, Biblioteca Básica Canaria, Gobierno de Canarias.

- (2007), Poesía surrealista (1931-1936), ed. de Isabel Castells, Santa Cruz de Tenerife, ediciones Idea y La Página.

Navarro Segura, Ma . Isabel (1997), «Eduardo Westerdahl y la construcción de Canarias como identidad espacial», en Emmanuel Guigon (coord.), Gaceta de Arte y su época, Las Palmas de Gran Canaria, C.A.A.M., págs. 23-73.

Paz, Octavio (1993²), Los hijos del limo, Barcelona, Seix Barral.

Pérez Corrales, José Miguel (1986), Agustín Espinosa entre el mito y el sueño, Cabildo Insular de Las Palmas de Gran Canaria.

Pérez MiniK, Domingo (1952), Antología de la poesía canaria I. Tenerife, Santa Cruz de Tenerife, Goya ediciones.

Rodríguez Padrón, Jorge (1992), Primer ensayo para un diccionario de la literatura en Canarias, Viceconsejería de Cultura y Deportes del Gobierno de Canarias.

RosA, José Ma . de la (1977), «La República, el Ateneo y Gaceta de Arte III», en El Día, Santa Cruz de Tenerife, 29 de octubre. 
RosA, Julio Antonio de la (1994), Tratado de las tardes nuevas, intr. de Isabel Castells, Santa Cruz de Tenerife, Gobierno de Canarias.

Westerdahl, Eduardo (1926), «Gente Nueva», en La Prensa, Santa Cruz de Tenerife, 12 de diciembre.

- (1927), «Aire de fado», en La Prensa, Santa Cruz de Tenerife, 7 de junio.

- (1929), «Acción de Pajaritas de Papel», en La Tarde, Santa Cruz de Tenerife, 31 de diciembre.

- (1931), «Cuaderno de Arte», en La Prensa, Santa Cruz de Tenerife, 6 de diciembre. 